В. Б. ОДЖАЕВ 1 , А. Н. ПЕТЛИЦКИЙ ${ }^{2}$ В. С. ПРОСОЛОВИЧ ${ }^{1}$, А. С. ТУРЦЕВИЧ ${ }^{2}$, С. В. ШВЕДОВ ${ }^{2}$, В. А. ФИЛИПЕНЯ ${ }^{2}$, В. В. ЧЕРНЫЙ, В. Ю. ЯВИД ${ }^{1}$, Ю. Н. ЯНКОВСКИЙ ${ }^{1}$ В. А. ДУБРОВСКИЙ

\title{
ВЛИЯНИЕ ТЕХНОЛОГИЧЕСКИХ ПРИМЕСЕЙ НА ЭЛЕКТРОФИЗИЧЕСКИЕ ПАРАМЕТРЫ МОП-ТРАНЗИСТОРА
}

\author{
${ }^{1}$ Белорусский государственный университет, \\ ${ }^{2}$ Открытое акичионерное общество «ИНТЕГРАЛ» - управляющзя компания холдинга «ИНТЕГРАЛ», \\ ${ }^{3}$ Белорусский национальный технический университет
}

(Поступила в редакцฺию 13.03.2014)

Введение. При производстве КМОП-структур требуется большое число технологических операций, особенно при использовании МДП-технологии [1-3]. Производственный контроль качества является составной частью типового технологического процесса и сводится к определению двух составляющих: явных дефектов, характеризующих процент выхода годных изделий, и скрытых дефектов, снижающих их надежность. Цели производственного контроля - получение требуемого качества приборов, своевременная отбраковка дефектных изделий на различных этапах изготовления. Важными являются выбор химических реактивов и такая последовательность технологических (особенно высокотемпературных) операций, которая в максимальной степени исключала бы попадание в структуру неконтролируемых (технологических) примесей. В связи с вышесказанным актуальным является выявление причин лабильной воспроизводимости основных характеристик МОП-транзисторов для установления факторов, определяющих надежность и стабильность эксплуатационных параметров интегральных микросхем.

Объекты и методы исследований. В работе на измерителе параметров полупроводниковых приборов Agilent B 1500 А с применением зондовой станции Cascide Summit 11000 (минимальный возможный измеряемый ток составлял примерно $10^{-15}$ А) исследованы вольт-амперные (BAX) характеристики МОП-транзисторов, изготовленных в разное время по эпитаксиальнопланарной технологии по аналогичным технологическим маршрутам при идентичных используемых технологических материалах (далее серии А и В). Карманы размером 70×70 мкм создавались на пластинах кремния $p$-типа проводимости с удельным сопротивлением 10 Ом-см ионным легированием бора для $p$-кармана, ионным легированием фосфора и мышьяка для $n$-кармана. Поликремниевый затвор, легированный до вырождения, имел размеры 10×10 мкм. Толщина подзатворного диэлектрика $\left(\mathrm{SiO}_{2}\right)$ равнялась 7 нм.

Экспериментальные результаты и их обсуждение. Сравнение выходных ВАХ МОП-структур (рис. $1, a, \sigma)$ показало, что приборы серии В обладают как более высокими значениями тока стока в режиме насыщения $\left(I_{c}\right)$, так и более высокими напряжениями отсечки. При напряжении на затворе $U_{3}=3,3 \mathrm{~B} I_{\mathrm{c}}=0,3$ мА для приборов серии $\mathrm{B}, I_{\mathrm{c}}=0,14$ мА для приборов серии А. Напряжение отсечки составляет соответственно 2,1 и 1,4 В. Если подвижность электронов $\mu_{n}$ не зави-

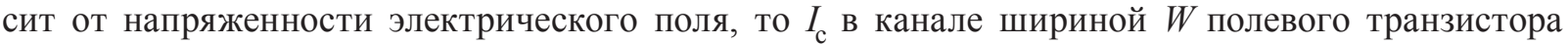
с изолированным затвором будет определяться следующим образом [4]:

$$
I_{\mathrm{c}}=\frac{1}{2} \mu_{n} \frac{W}{L} C_{\text {д }}\left(U_{3}-U_{\text {пор }}\right)^{2},
$$

где $C_{\text {д }}$ - удельная емкость диэлектрика, $U_{\text {пор }}$ - пороговое напряжение. 

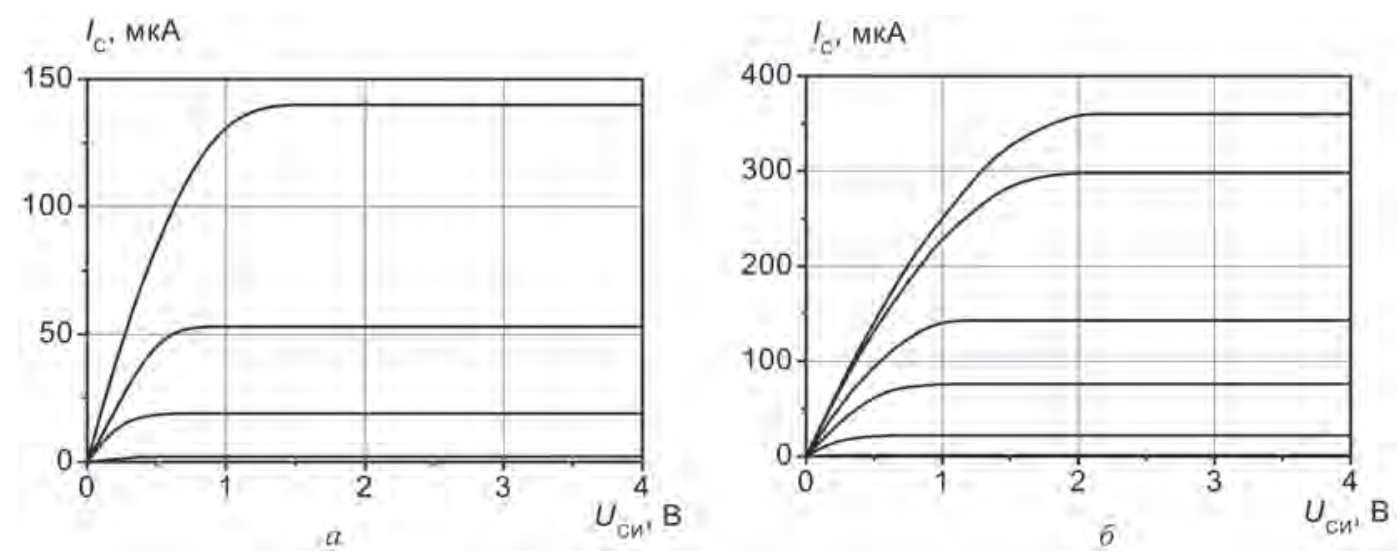

Рис. 1. Выходные характеристики МОП-структур с каналом $n$-типа серий А $(a)$ и В (б) $\left(U_{3}=0-6 \mathrm{~B}\right.$, шаг $\left.1 \mathrm{~B}\right)$

Из выражения (1) видно, что при $U_{3}=$ const и при $W / L=$ const наблюдаемые различия в величине $I_{\mathrm{c}}$ в первую очередь можно связать с изменением напряжения отсечки $U_{\mathrm{p}}=U_{3}-U_{\text {пор }}$. Поскольку отношения экспериментальных значений $I_{\mathrm{c}}^{\mathrm{B}} / I_{\mathrm{c}}^{\mathrm{A}}=0,30 \mathrm{MA} / 0,14 \mathrm{MA}=2,14$ и $\left(U_{\mathrm{p}}^{\mathrm{B}} / U_{\mathrm{p}}^{\mathrm{A}}\right)^{2}=$ $(1,7 \mathrm{~B} / 1,2 \mathrm{~B})^{2}=2,01\left(U_{3}=3,3 \mathrm{~B}\right)$ хорошо коррелируют между собой и согласуются с формулой $(1)$, то можно сделать вывод, что отличия $I_{\mathrm{c}}$ и $U_{\mathrm{p}}$ для приборов серий А и В обусловлены одной и той же причиной, которая, по-видимому, определяет величину порогового напряжения $U_{\text {пор }}$ :

$$
U_{\text {пор }}=2 \psi_{B}+\frac{\sqrt{2 \varepsilon_{S} q N_{A}\left(2 \psi_{B}\right)}}{C_{\text {д }}},
$$

где $\psi_{B}$ - разность между уровнем Ферми в используемом материале и в собственном полупроводнике, $N_{A}$ - концентрация легирующей примеси $p$-подложки. Из выражения (2) следует, что причиной изменения $U_{\text {пор }}$ (при условии однородного легирования подложки) является непостоянство $C_{\text {д, }}$ связанное с неконтролируемым зарядом, локализованным в области МОП-конденсатора (затвора). Из анализа ВАХ определен также ряд других важных параметров МОПструктуры: ток насыщения, ток стока, проводимость МОП-транзистора в линейной области BAX, крутизна характеристики МОП-транзистора в линейной области, крутизна характеристики МОП-транзистора в области насыщения (табл. 1). Видно, что для транзисторов из серии А (табл. 1) значение тока и напряжения насыщения, крутизна в линейной области и в области насыщения, проводимость в линейной области меньше, чем у транзисторов из серии В. В то же время значение порогового напряжения у транзисторов из серии А выше, чем у транзисторов из серии В. Одна из возможных причин отличия параметров транзисторов, вероятно, также связана с величиной емкости подзатворного диэлектрика и его качеством, обусловленными наличием встроенного заряда. Для проверки данного предположения проведено сравнение отношения емкостей подзатворного диэлектрика МОП-транзисторов из серий А и В $\left(C_{i \mathrm{~A}} / C_{i \mathrm{~B}}\right)$, определенных на различных участках $\mathrm{BAX}[5,6]$ исходя из проводимости в линейной области, крутизны характеристики в линейной области, величины тока насыщения, крутизны в области насыщения (табл. 2).

Т а б л и ц а 1. Параметры МОП-транзисторов, определенные из анализа вольт - амперных и стоковых характеристик

\begin{tabular}{|l|c|c|}
\hline \multicolumn{1}{|c|}{ Параметр МОП-транзистора } & Серия А & Серия В \\
\hline Ток насыщения $I_{\text {с нас }}$ при $U_{3}=3,3 \mathrm{~B}$, мкА & 138 & 280 \\
\hline Напряжение насыщения $U_{\text {си нас }}, \mathrm{B}$ & 1,20 & 1,90 \\
\hline Пороговое напряжение $U_{\text {пор }}, \mathrm{B}$ & 1,25 & 0,76 \\
\hline Крутизна характеристики МОП-транзистора в линейной области при $U_{\mathrm{cu}}=0,2 \mathrm{~B}, \mathrm{м \kappa} \mathrm{A} / \mathrm{B}$ & 19 & 22,1 \\
\hline Крутизна характеристики МОП-транзистора в области насыщения при $U_{\text {си }}=2,9 \mathrm{~B}, \mathrm{M \kappa} \mathrm{A} / \mathrm{B}$ & 100,3 & 175 \\
\hline Проводимость МОП-транзистора в линейной области при $U_{\text {зи }}=0,2 \mathrm{~B}, \mathrm{M \kappa} \mathrm{A} / \mathrm{B}$ & 174 & 274 \\
\hline
\end{tabular}


Т а б л и ц а 2. Отношение удельных емкостей подзатворного диэлектрика транзисторов в сериях А и В

\begin{tabular}{|l|c|c|}
\hline \multicolumn{1}{|c|}{ Метод определения } & Напряжение на затворе и стоке & $\mathrm{C}_{\mathrm{i \AA}} / \mathrm{C}_{\mathrm{iB}}$ \\
\hline По проводимости & $U_{\text {си }}=0,2 \mathrm{~B}, U_{\text {зи }}=3,3 \mathrm{~B}$ & 0,79 \\
\hline По крутизне в линейной области & $U_{\text {си }}=0,2 \mathrm{~B}$ & 0,86 \\
\hline По току насыщения & $U_{3 и}=3,3 \mathrm{~B}$ & 0,76 \\
\hline По крутизне в области насыщения & $U_{\text {си }}=3,5 \mathrm{~B}, U_{3 и}=2,9 \mathrm{~B}$ & 0,75 \\
\hline
\end{tabular}

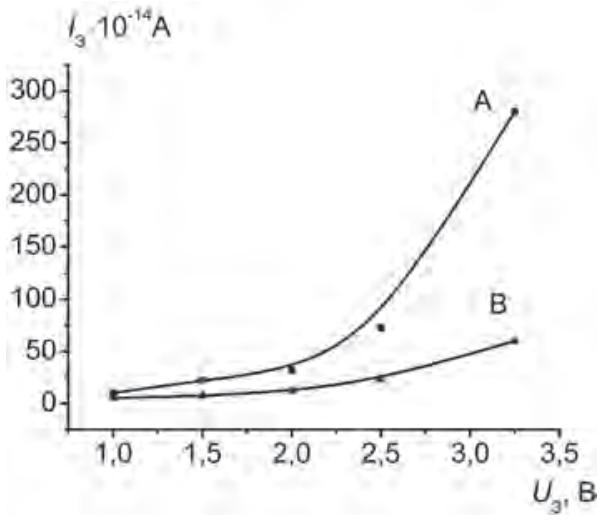

Рис. 2. Зависимость тока утечки затвора МОП-структуры от напряжения на затворе
Из табл. 2 следует, что вне зависимости от метода оценки отношения $C_{i \mathrm{~A}} / C_{i \mathrm{~B}}$ значение емкости $C_{i \mathrm{~B}}$ выше величины емкости $C_{i \mathrm{~A}}$ приблизительно на $20 \%$, что однозначно свидетельствует о дополнительном заряде $[2,4,5,7]$ встроенном в слой окисла подзатворного диэлектрика МОП-транзисторов серии А. Это обусловлено тем, что на границе раздела $\mathrm{Si}-\mathrm{SiO}_{2}$, полученной термическим окислением кремния, всегда присутствуют четыре различных по своей природе источника заряда: заряд быстрых поверхностных состояний в полупроводнике, постоянный заряд в окисле, заряд на ловушках в слое окисла и заряд подвижных ионов.

Энергетическая плотность быстрых поверхностных состояний непосредственно на границе $\mathrm{Si}-\mathrm{SiO}_{2}$ сильно зависит от режима получения окисла. Величина постоянного заряда в окисле зависит от режима окисления, условий отжига и вида предокислительных обработок кремниевых пластин и загрязнения системы $\mathrm{Si}-\mathrm{SiO}_{2}$ катионными примесями. Заряд на ловушках в слое окисла представляет собой объемный заряд, захваченный на энергетические уровни дефектов в $\mathrm{SiO}_{2}$. Этот тип заряда ассоциируется с медленными поверхностными состояниями. Заряд подвижных ионов связан с присутствием в окисле ионов щелочных $\left(\mathrm{Na}^{+}, \mathrm{K}^{+}, \mathrm{Li}^{+}\right)$ и тяжелых металлов, попадающих в окисел из окружающей среды, и материалов, используемых в технологическом процессе.

Исследованиями тока утечки (рис. 2) установлено, что величина тока через подзатворный диэлектрик для структур из серии В ниже соответствующего тока для структур из серии А примерно в 5 раз. Это свидетельствует о том, что электрическое сопротивление пленок подзатворного диэлектрика у структур серии В выше, чем у аналогичных структур серии А. Причиной наблюдаемых различий, вероятно, является существенное загрязнение подзатворного диэлектрика приборов серии А технологическими примесями в процессе их изготовления. Такими загрязнениями могут быть ионы щелочных металлов $\left(\mathrm{Na}^{+}, \mathrm{K}^{+}, \mathrm{Li}^{+}\right)$и тяжелых металлов, адсорбированные на поверхности, кислородные вакансии, ловушки в окисле, полярные молекулы, попадающие в окисел из окружающей среды во время технологического процесса изготовления приборов. Действительно, исследования на рентгенофлуоресцентном спектрометре Rigaku TXRF 3750 содержания металлических примесей на поверхности пластин методом полного внешнего отражения рентгеновского излучения $[8,9]$ показали, что вся поверхность пластин из серии А покрыта слоем Fe со средней концентрацией $3,4 \cdot 10^{11}$ ат/см². Наблюдаются также пятна $\mathrm{Cl}, \mathrm{K}, \mathrm{Ca}, \mathrm{Ti}$, $\mathrm{Cr}, \mathrm{Cu}, \mathrm{Zn}$. На пластинах серии В наблюдаются только пятна $\mathrm{Cl}$ по периферии пластины. Содержание всех остальных примесей было ниже предела обнаружения (по $\mathrm{Fe}<4,0 \cdot 10^{9}$ ат $/ \mathrm{cm}^{2}$ ).

Заключение. Установлено, что электрофизические характеристики МОП-транзисторов существенным образом зависят от качества подзатворного диэлектрика. Наличие дополнительного встроенного заряда в диэлектрике, а также быстрых поверхностных состояний на границе раздела $\mathrm{Si}-\mathrm{SiO}_{2}$ приводит как к увеличению порогового напряжения, так и снижению тока и напряжения насыщения, крутизны характеристики МОП-транзистора в линейной области и в области насыщения, проводимости структуры в линейной области. Возрастают также токи утечки затвора. Наиболее вероятной причиной ухудшения электрофизических параметров МОП-тран- 
зисторов является загрязнение материала технологическими примесями ( $\mathrm{Fe}, \mathrm{Cl}, \mathrm{Ca}, \mathrm{Cu}, \mathrm{Zn}$ и др.) во время производственного процесса изготовления приборов. Источниками загрязнений могут служить как детали и узлы технологических установок, так и используемые материалы и реактивы.

\section{Литература}

1. Базовые технологические процессы изготовления полупроводниковых приборов и интегральных микросхем на кремнии / Под ред. А. С. Турцевича. В 3 т. Мн., 2013. С. 302-504.

2. Лебедев А. И. Физика полупроводниковых приборов. М., 2008. С. 239-294.

3. Ефимов И. Е., Козырь И. Я., Горбунов Ю. И. Микроэлектроника. Физические и технологические основы, надежность. М., 1986. С. 20-39.

4. 3и С. М. Физика полупроводниковых приборов (перевод с английского) в двух частях. М., 1984. С. 5-90.

5. Денисенко В. В. // Компоненты и технологии. 2009. № 12. С. 35-48.

6. Бочаров Л. Н. Полевые транзисторы. М., 1984 С. 42-59.

7. Зи С. М. Технология СБИС. В 2 кн. М., 1986. С. 120-127.

8. SEMI M33-0988

9. Berneike W., Knoth J., Schwenke H., Weisbrod U.// Fresnius Z. Anal. Chem. 1989. Vol. 333. P. 524-526.

V. B. ODZAEV, A. N. PYATLITSKI, V. S. PRASALOVICH, A. S. TURTSEVICH, S. V. SHVEDAU, V. A. FILIPENIA, V. V. CHORNY, V. Yu. YAVID, Yu. N. YANKOUSKI, V. A. DUBROUSKI

\section{INFLUENCE OF TECHNOLOGICAL IMPURITIES ON ELECTRICAL PARAMETERS OF MOS TRANSISTOR}

\section{Summary}

It is shown that the quality of gate dielectric has a determinative impact on electrical physical parameters of MOS transistors. Contamination of material by technological impurities during the manufacturing process is the reason for the deterioration of electrical physical parameters of MOS transistors. Sources of contamination can be components of technological equipments, as well as the materials and reagents. 